CORRESPONDENCE

Table 1

\begin{tabular}{lccc}
\hline & Baseline & After 100 ECT & After 125 ECT \\
\hline Raw scores on CAPE & & & \\
information orientation (max. 12) & 12 & 12 & 12 \\
mental ability (max. 11) & 11 & 11 & 11 \\
psychomotor skill (max. 12) & 11 & 11 & 11 \\
Premorbid IQ & 103 & 105 & 108 \\
Contemporaneous 10 & 99 & 100 & 100 \\
\hline
\end{tabular}

contemporaneous IQ, estimated using the Mill Hill Vocabulary Scale (Raven et al, 1982), was almost exactly the average at the initial onset and did not differ from her predicted premorbid IQ (National Adult Reading Test; Nelson, 1982): this did not change.

A single case study cannot resolve the continuing debate about ECT and brain damage, but the present case is unique in the literature and shows clearly that a prolonged course of bilateral ECT had no effect upon the intellectual abilities assessed. Long-term prospective studies that cover a wider range of intellectual functions are still required.

Breggn, P. (1993) Toxic Psychiatry: Drugs and Electroconvulsive Therapy - The Truth and Better Alternatives. London: Fontana.

Nelson, H. E. (1982) National Adult Reading Test: Test Manual. Windsor: NFER

Pattie, A. H. \& Guillard, C. J. (1979) The Clifton Assessment Procedure for the Elderly. Seven Oaks: Hodder and Stoughton. Raven, J. C., Raven, J. \& Court, J. H. (1982) The Mill Hill Vocabulary Scale, Form 2 Senior. London: H.K. Lewis.

Scott, A. I. F., Turnbull, L. W., Blane, A., et al (1991)

Electroconvulsive therapy and brain damage. Lancet, 338, 284.

A. G. HaY

Royal Edinburgh Hospital

A. I. F. SCOTT

Edinburgh ENI0 5HF

\section{Volunteers to help Bosnian refugees}

SIR: We are hoping to set up a project offering psychiatric and counselling support for the Bosnian refugees in the London area. The refugees have almost without exception been subjected to appalling psychological and physical trauma, including torture, rape, and detention in concentration camps. Many of the survivors suffer from posttraumatic stress disorder (PTSD), and a small proportion are affected by major psychiatric illness, including severe depression and psychotic reactions. There is a lack of appropriate and accessible health and social services for refugees and asylum-seekers and this project is a collaboration between the Traumatic Stress Clinic (Camden and Islington
Community Trust), which is a national referral centre specialising in therapeutic interventions for people with PTSD, and psychiatrists at Guy's Hospital with an interest in transcultural psychiatry and a history of service development for the Indo-Chinese refugee community.

The Bosnian project is coordinated by the Jewish Council for Community Relations and is working in association with the Department of Child Psychiatry at the Royal Free Hospital, the Marborough Family Service, the Medical Foundation for the Victims of Torture, the Refugee Council, and the Bosnian Embassy. The bulk of the therapeutic activity will be carried out by bi-cultural workers using cognitive models of intervention developed and evaluated within the Traumatic Stress Clinic using methods successfully used within a specialist service for survivors of organised violence in Turkey (Yuksel, 1990). The bi-cultural workers will screen people who have evidence of major psychiatric disorder, who will be referred to a network of mental health practitioners. This team of practitioners will be able to carry out domiciliary and community assessments, with the help of interpreters.

Psychiatrists, community psychiatric nurses and other mental health professionals who wish to participate in this project on a voluntary basis should contact Dr Edie Friedman on 081455-0896. We are also looking for charitable funding.

Yuksel S. (1990) Post-traumatic cognitive behaviour therapy. Proceedings of the Second European Conference on Traumatic Stress, p. 58. Netherlands: Noordwijkerhort.

STUART TURNER

Camden \& Islington CHS (NHS) Trust

112 Hampstead Road

London NWI $2 L T$

Department of Psychiatry

MAURICE LiPSEDGe

Guy's Hospital,

London 